TP Periodica Polytechnica

42(2), pp. 167-172, 2014

DOI:10.3311/PPtr.7403

Creative Commons Attribution (1)

RESEARCH ARTICLE

\section{Coherence between Horizontal and Vertical Curves and the Number of the Accidents}

Tibor Sipos

RECEIVED 15 DECEMBER 2013

\begin{abstract}
The authors analysed a network element of the A-level road network. Road Nr. 82.was analysed in order to determine the difference between the characteristic of the existing road network and referred parameters of the road design regulations. It was proved trough accidental statistics and geoinformatics analyses that there was coherence between horizontal and vertical curves and the number and the severity of the accidents on the road Nr. 82.
\end{abstract}

\section{Keywords}

road safety ' infrastructure $\cdot$ design $\cdot$ road infrastructure evaluation

Tibor Sipos

Department of Transport Technology and Economics,

Faculty of Transportation Engineering and Vehicle Engineering,

Budapest University of Technology and Economics,

Stoczek u. 2., H-1111 Budapest, Hungary

e-mail: tsipos@kgazd.bme.hu

\section{Introduction}

A key factor for the safety of road transport is the infrastructure design (Török, 2013). Considering the cost structure, combining infrastructure investments with speed management can be expected to yield double of the results as compared to spending these amounts on vehicle development or on changing the behavior of the drivers. "Self-explanatory" roads decrease the number of accidents by showing the participants of road transport where they should be progressing and how they can safely use the public roads (Bosurgi, 2013). "Forgiving" roads protect the participants of road transport if the accidents happen.

The sector accepts the fact that infrastructure design has a direct influence on transport safety, however, there is further development needed in the area of the investigation methods regarding the analysis of the relationship between the road parameters and transport safety risk (Dabbour, 2012; Podvezko and Sivilevičius 2013). Thus the aim of the present study is to investigate the correlation between the road design characteristics and transport safety risk.

\section{Methodology of the on-site measurement}

In this work we focus on places and sites constituting constant danger. We investigate specifically the typical solutions to the problems these represent and the deviations from these. Thus the aim was to carry out the measurement at a reference road where outlying vertical and horizontal curves, hence also the increased presence of dangerous sites and turns could be expected. As a reference road, the main road No. 82. from Veszprém to the county border (from $0+000$ to $76+156$.) was chosen based on Baranyai (2012) (Fig. 1.).

The measurement was carried out by a measurement unit and a data processing software developed for the given purpose. The measurement unit consisted of a camera and a GPS device [(Fig. 2.) The test car.]. Accurate measurement is only possible if the image from the camera and the data from the GPS can be displayed in real time and in a synchronized way on one screen.

The measurement was carried out by $90 \mathrm{~km} / \mathrm{h}$, thus we moved with the test car approximately 25 meters between the locations of the GPS data recorded in every second. This 


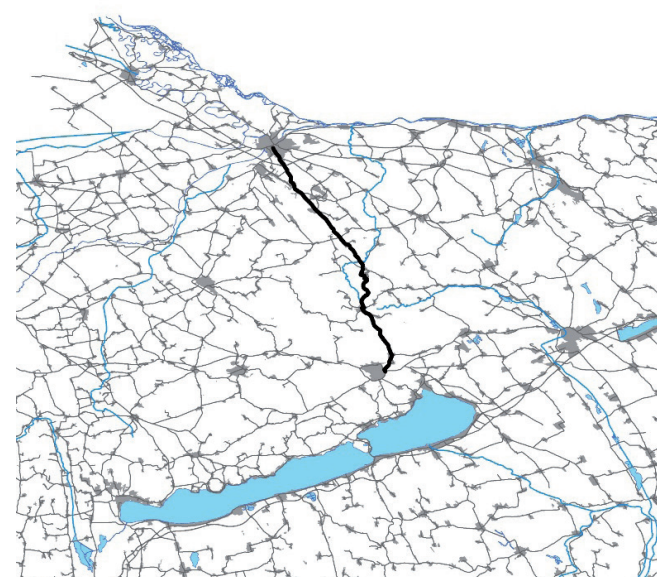

Fig. 1. Position of main road No. 82. (in black)

proved to be dense enough to enable reliable analysis and retrospective calculations. The software stores the video recordings as images. It records 10 images in each second and also creates a data batch enabling position identification. This way the measurement results can be displayed graphically by the ArcMap software (Sipos and Török, 2010).

The sector accepts the fact that infrastructure design has a direct influence on transport safety, however, there is further development needed in the area of the investigation methods regarding the analysis of the relationship between the road parameters and transport safety risk. Thus the aim of the present study is to investigate the correlation between the road design characteristics and transport safety risk.

\section{Data processing}

The data collected by the GPS are recorded in the so called WGS'84 (World Geodetic System) projection system. In this ellipsoidal coordinate system, every point is described by 3 data: the latitude $(\Phi)$, the longitude $(\Lambda)$ and the altitude $(\mathrm{z})$. To derive the geographical information of the road investigated, these coordinates are to be transformed. In this transformation the WGS'84 reference ellipsoid is projected onto a plane. In the present work the Uniform National Projection System (HD72), which is in use since 1972 in Hungary, has been applied. This is a reduced cylindrical map projection applicable for geodesic and geometric investigations. The prime meridian of the UNP system is that running through Gellért Hill. Coordinate transformation from the WGS' 84 coordinate system to the UNP system is carried out by double projection.

\section{Geometric analysis}

In the course of the horizontal geometric analysis of the road section, 3 different geometric elements have been defined based on (Wanty et al., 1995):

1. Straight sections

2. Arc sections

3. Arbitrary curve sections

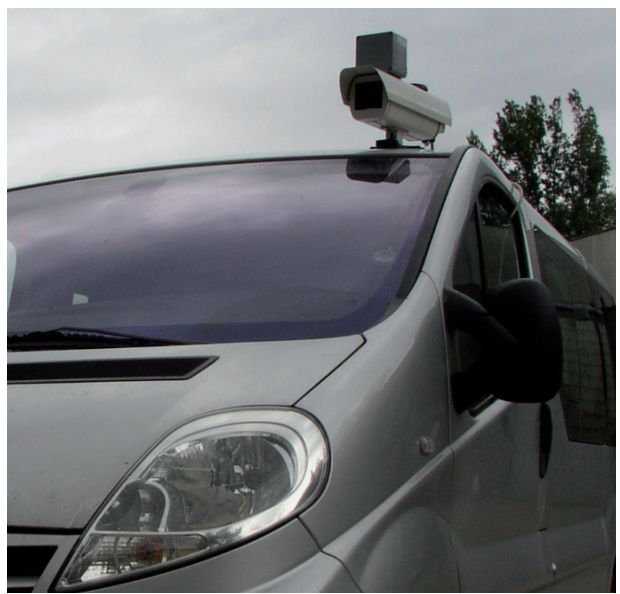

Fig. 2. The test car

The following algorithm has been designed to differentiate between and determine the different sections:

\subsection{Straight sections}

The straight lines are determined by the least squares method. A straight line characterized by the expression (1):

$$
\hat{Y}=A X+B
$$

is fit to the $\mathrm{X}, \mathrm{Y}$ coordinates given in the UNP coordinate system (Varga, 1982; Varga, 2003), where A and B are the parameters of the straight line. Those parameter values are sought which minimize the following squared residuals (2):

$$
J(A, B)=\sum_{i=1}^{N}\left(\hat{Y}_{i}-Y_{i}\right)^{2}
$$

where $\mathrm{N}$ indicates the number of data points. The quality of fitting is characterized by $\mathrm{R}^{2}$ which is defined by the following (3):

$$
R^{2}=1-\frac{\sum_{i=1}^{N}\left(\hat{Y}_{i}-Y_{i}\right)^{2}}{\sum_{i=1}^{N}\left(\bar{Y}_{i}-Y_{i}\right)^{2}}
$$

where $\bar{Y}$ indicates is the average value of the measured points. $\mathrm{R}^{2}$ characterizes the linear regression: the closer it is to 1 , the better the linear relationship.

Our aim was to define straight sections which are as long as possible. In order to do that, we applied a sequential procedure, in which the number of the data points was gradually increased. Starting with the beginning coordinates of the road section, a straight line was fit first on the first 3 measured points, and then $\mathrm{R}^{2}$ was checked. If the result was higher than a predetermined threshold value, then one more data point was included and fitting was repeated, while its goodness was also checked. This was continued until $\mathrm{R}^{2}$ did not drop below the threshold value. Thus the straight sections present in the data series could be determined, which were recorded by storing their beginning and end point, just as well as their length. 
Subsequently these data were not to be used any more, the remaining data series now comprised only points which could be described by arcs or arbitrary curve sections.

\subsection{The arc sections}

The arc sections are determined by optimisation, in the course of which the points of the sections between the end points of the previously determined straight lines are analysed. To attain the best possible fit, a two step optimisation is applied:

In the first step, the algebraic representation of the circle is used, which can be expressed by the following equation (4):

$$
F(Z)=A Z^{T} Z+B^{T} Z+C=0
$$

In the algebraic form, $Z$ designates the points in the plane, while $A, B$ and $C$ are the coefficients to be determined. Ordering these parameters into a vector $P$, a linear optimisation problem is acquired with the objective of minimizing function $\mathrm{F}(\mathrm{Z})$. To avoid getting the trivial solution, a limiting condition is introduced (5):

$$
\|P\|=1
$$

The advantage of the procedure is the fact that it is easy to be calculated numerically, but it has the disadvantage of not always providing a suitable result as it is minimizing the algebraic distance. To have a better fit, the geometric distance is to be minimized.

The geometric distance of a given $x_{i}$ point from a circle with its centre in $O$, and with radius $R$ can be defined with the following expression (6):

$$
d_{i}^{2}=\left(\left\|O-x_{i}\right\|-R\right)^{2}
$$

If there are $N$ measurements available, then the error function derived from the distances takes on the following shape (7):

$$
\sum_{i=1}^{N} d_{i}(O, R)^{2}
$$

Minimizing the error function necessitates non-linear optimization, where those values of $\mathrm{O}$ and $\mathrm{R}$ are sought which ensure the smallest geometric distance. The Gauss-Newton iterative procedure is applied to solve the problem. As initial values, the parameters of the circle resulting from minimizing the algebraic error were used (determined in the previous step).

The road sections whose geometry can be appropriately described by an arch can be identified by this two step procedure. If the geometric error is above the threshold value, the approximation by a circle is ruled out, and the section is considered to be an arbitrary curve (of a variable arc). These sections are described in the third step of the geometric analysis.

\subsection{Arbitrary curve sections}

The data points which cannot be described either by a straight line or an arc are mathematically modelled by third-degree spline interpolation (Lyche and Schumacker, 1973). In the course of this, the interpolation function consisting of the following sections is fitted to the $N$ data points (8):

$$
S(x)=\left\{\begin{array}{cc}
S_{1}(x), & x \in\left[x_{1}, x_{2}\right] \\
\ldots & \ldots \\
S_{N-1}(x), & x \in\left[x_{N-1}, x_{N}\right]
\end{array}\right.
$$

Furthermore, the individual spline polinoms are presumed to be of third degree, i.e. (9):

$$
S_{i}(x)=a_{i}\left(x-x_{i}\right)^{3}+b_{i}\left(x-x_{i}\right)^{2}+c_{i}\left(x-x_{i}\right)+d_{i}
$$

The spline function has to fulfil the following conditions:

- The $S(x)$ section function interpolates all points,

- $S(x)$ is continuous on the domain $\left[x_{1}, x_{N}\right]$,

- $S(x)^{\prime}$ is continuous on the domain $\left[x_{1}, x_{N}\right]$,

- $S(x)^{\prime \prime}$ is continuous on the domain $\left[x_{1}, x_{N}\right]$.

The coefficients $a_{i}, b_{i}, c_{i}$, and $d_{i}(i=1 \ldots N)$ of the spline functions can be calculated as the solution of the system of algebraic equations resulting from the above characteristics. The spline functions characterizing the sections having been determined for the intervals of the data points, the local curvature $(\kappa)$ and the radius of the local tangent sphere $(\rho)$ can be determined. The relevant closed-form expressions are (10 and 11):

$$
\begin{gathered}
\kappa_{i}(x)=\frac{S_{i}^{\prime}(x)}{\left(1+\left(S_{i}^{\prime \prime}(x)\right)^{2}\right)^{3 / 2}} \\
\rho_{i}(x)=\frac{1}{\kappa_{i}(x)} .
\end{gathered}
$$

These parameters convey important information about the given road section as it will be shown in the next chapter on the calculation of transport safety parameters.

\section{Analysis}

Having determined the straight sections, the next step is to identify the curve sections. First those sections were identified, which can be well characterized by an arc. Fig. 3. presents the circles fitted by the algorithm (and also the straight sections).

The algorithm identified 31 sections describable by arcs, the radius of which was between $90 \mathrm{~m}$ and $7.5 \mathrm{~km}$. The histogram in Fig. 4. shows the frequency of the different circle sizes.

Finally the spline interpolation was carried out. In Fig. 5. those 9 sections describable by an arbitrary curve have been coloured in black which were fitted with third-degree spline functions.

Using the analytic form of the functions, the radius of the local tangent sphere applicable in the given point was calculated, the frequency distribution of which is shown in Fig. 6.

Finally, the vertical profile of main road No. 82. is shown in Fig. 7. 


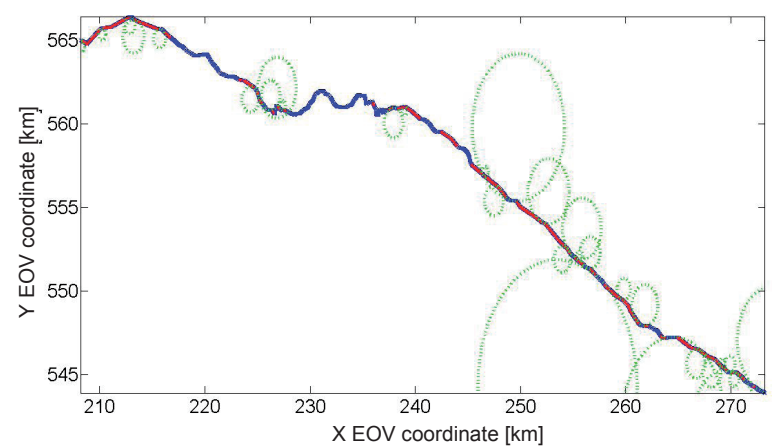

Fig. 3. Arcs

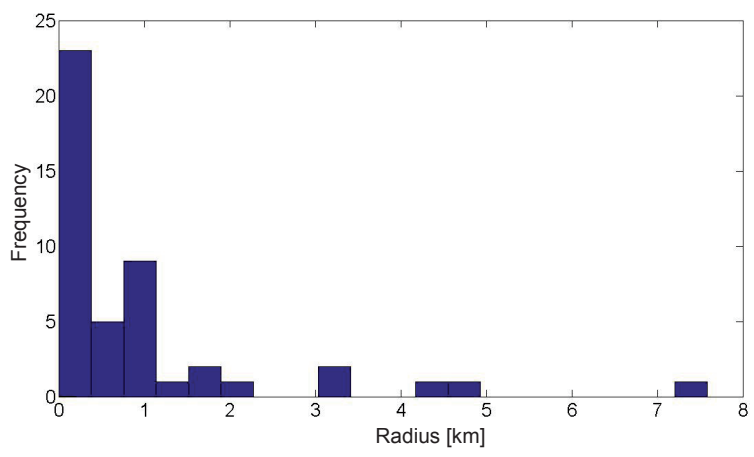

Fig. 4. Frequency distribution of the different circle sizes

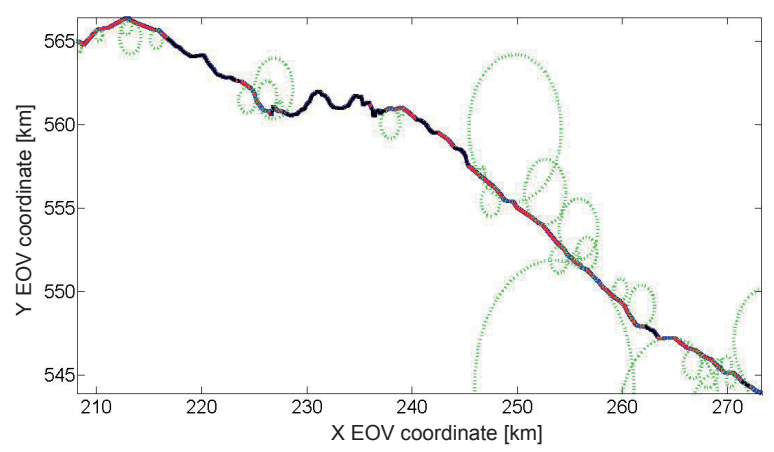

Fig. 5. Sections, which can be characterized by spline interpolation

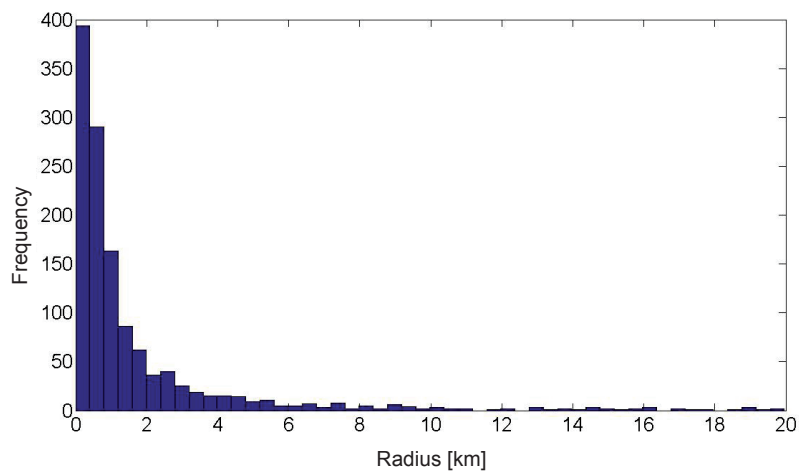

Fig. 6. Frequency distribution of the radius of the local tangent spheres

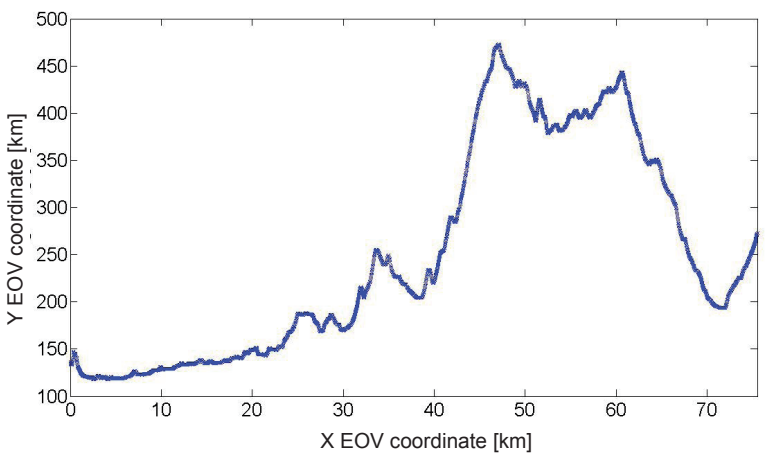

Fig. 7. The vertical profile of main road No. 82 .

\section{Evaluation}

Having analysed main road No. 82., the next step is to investigate the relationship between the characteristics of the infrastructure and transport safety risk. Regarding the infrastructure, the explanatory variables are the radius of the arcs and the steepness of the slopes as the characteristic features of the vertical and horizontal profile.

As a dependent variable it is reasonable to choose a parameter, which describes the transport safety risk characterizing the investigated road section in such a way that it both represents the number (probability of the event) and possible outcome (severity) of the expected accidents on the route based on the EuroRAP methodology (Holló et al., 2011).

To this aim, relative indicators representing the relationship of the number of accidents, the severity of the accidents and the length of the route concerned are applied.

In the course of evaluation, the given route is divided into sections and these sections are then clustered according to the infrastructure design characteristics. The sections are created as based on the GPS coordinates recorded during the on-site measurement, with a frequency of approximately $30 \mathrm{~m}$.

As a result a database is produced, its records are the sections of the given route. Each section can be put into an arc radius and a steepness category. E.g. if the arc radius of the record is below $25 \mathrm{~m}$, then it shall be put into arc radius category No. 1 . According to this, the arc radius and steepness attributes stored in the database contain the category number describing the infrastructure design.

Tab. 1. Clustering of the sample [numbers]

1. shows the numerical results received after clustering the data from the measurement. As based on this it can be stated that the number of elements in the sample are increasing roughly gradually from the left upper corner to the right lower corner.

There are relatively fewer sections of steep slopes with small radius, while the dominant part of the sample is made up of straight and horizontal sections. This is also shown by the colour codes, as the colour scale of the table shifts gradually from green indicating the lower values, through yellow to red indicating the salient values. 
Tab. 1. Clustering of the sample [numbers]

\begin{tabular}{|l|c|c|c|c|c|c|c|}
\hline $\mathrm{R}[\mathrm{m}] / \mathrm{e}[\%]$ & $8-12$ & $7-8$ & $6-7$ & $5,5-6$ & $5-5,5$ & $4-5$ & $0-4$ \\
\hline $0-25$ & 0 & 0 & 3 & 1 & 1 & 2 & 9 \\
\hline $25-45$ & 0 & 1 & 0 & 0 & 1 & 0 & 8 \\
\hline $45-80$ & 0 & 0 & 3 & 1 & 1 & 1 & 20 \\
\hline $80-120$ & 0 & 0 & 4 & 3 & 5 & 4 & 25 \\
\hline $120-180$ & 0 & 3 & 1 & 5 & 0 & 6 & 55 \\
\hline $180-250$ & 1 & 1 & 4 & 1 & 8 & 13 & 68 \\
\hline $250-340$ & 2 & 2 & 3 & 5 & 11 & 12 & 146 \\
\hline $340-450$ & 2 & 2 & 5 & 4 & 10 & 13 & 122 \\
\hline $450-600$ & 2 & 0 & 6 & 3 & 5 & 8 & 173 \\
\hline $600-900$ & 0 & 3 & 7 & 6 & 7 & 12 & 188 \\
\hline $900-2000$ & 1 & 3 & 9 & 21 & 24 & 39 & 418 \\
\hline $2000-5000$ & 8 & 6 & 11 & 3 & 9 & 22 & 267 \\
\hline $5000-20000$ & 0 & 1 & 4 & 3 & 3 & 6 & 122 \\
\hline $20000-100000$ & 1 & 3 & 12 & 14 & 39 & 80 & 1724 \\
\hline
\end{tabular}

Tab. 2. Fatalities 2008-2010

\begin{tabular}{|l|c|c|c|c|c|c|c|}
\hline $\mathrm{R}[\mathrm{m}] /$ e $[\%]$ & $8-12$ & $7-8$ & $6-7$ & $5,5-6$ & $5-5,5$ & $4-5$ & $0-4$ \\
\hline $0-25$ & 0 & 0 & 0 & 0 & 0 & 0 & 1 \\
\hline $25-45$ & 0 & 0 & 0 & 0 & 0 & 0 & 0 \\
\hline $45-80$ & 0 & 0 & 0 & 0 & 0 & 0 & 0 \\
\hline $80-120$ & 0 & 0 & 0 & 0 & 0 & 0 & 1 \\
\hline $120-180$ & 0 & 0 & 0 & 0 & 0 & 0 & 0 \\
\hline $180-250$ & 0 & 0 & 0 & 0 & 0 & 0 & 0 \\
\hline $250-340$ & 0 & 0 & 0 & 0 & 0 & 0 & 0 \\
\hline $340-450$ & 0 & 0 & 0 & 0 & 0 & 0 & 0 \\
\hline $450-600$ & 0 & 0 & 0 & 0 & 0 & 0 & 0 \\
\hline $600-900$ & 0 & 0 & 0 & 0 & 0 & 0 & 0 \\
\hline $900-2000$ & 0 & 0 & 0 & 0 & 0 & 0 & 2 \\
\hline $2000-5000$ & 0 & 0 & 0 & 0 & 1 & 0 & 2 \\
\hline $5000-20000$ & 0 & 0 & 0 & 0 & 0 & 0 & 0 \\
\hline $20000-100000$ & 0 & 0 & 0 & 0 & 0 & 0 & 2 \\
\hline
\end{tabular}

If the number of injuries from the accidents in the given sections are assigned to the infrastructure design categories, then the number of injuries in a given infrastructure design group can be established.

As based on Tab 2. below, it can be stated that the majority of fatal accidents happened in horizontal sections, which is not surprising, since more than $86 \%$ of the route can be characterized by a lengthwise slope between 0 and $4 \%$.

The assessment of the results from the table above is facilitated by expressing the number of fatalities in the infrastructure design classes as the percentage of fatalities on the entire route.
Tab. 3. Distorsition of fatalities in percentages

\begin{tabular}{|l|c|c|c|c|c|c|c|}
\hline $\mathrm{R}[\mathrm{m}] / \mathrm{e}[\%]$ & $8-12$ & $7-8$ & $6-7$ & $5,5-6$ & $5-5,5$ & $4-5$ & $0-4$ \\
\hline $0-25$ & $0 \%$ & $0 \%$ & $0 \%$ & $0 \%$ & $0 \%$ & $0 \%$ & $11 \%$ \\
\hline $25-45$ & $0 \%$ & $0 \%$ & $0 \%$ & $0 \%$ & $0 \%$ & $0 \%$ & $0 \%$ \\
\hline $45-80$ & $0 \%$ & $0 \%$ & $0 \%$ & $0 \%$ & $0 \%$ & $0 \%$ & $0 \%$ \\
\hline $80-120$ & $0 \%$ & $0 \%$ & $0 \%$ & $0 \%$ & $0 \%$ & $0 \%$ & $11 \%$ \\
\hline $120-180$ & $0 \%$ & $0 \%$ & $0 \%$ & $0 \%$ & $0 \%$ & $0 \%$ & $0 \%$ \\
\hline $180-250$ & $0 \%$ & $0 \%$ & $0 \%$ & $0 \%$ & $0 \%$ & $0 \%$ & $0 \%$ \\
\hline $250-340$ & $0 \%$ & $0 \%$ & $0 \%$ & $0 \%$ & $0 \%$ & $0 \%$ & $0 \%$ \\
\hline $340-450$ & $0 \%$ & $0 \%$ & $0 \%$ & $0 \%$ & $0 \%$ & $0 \%$ & $0 \%$ \\
\hline $450-600$ & $0 \%$ & $0 \%$ & $0 \%$ & $0 \%$ & $0 \%$ & $0 \%$ & $0 \%$ \\
\hline $600-900$ & $0 \%$ & $0 \%$ & $0 \%$ & $0 \%$ & $0 \%$ & $0 \%$ & $0 \%$ \\
\hline $900-2000$ & $0 \%$ & $0 \%$ & $0 \%$ & $0 \%$ & $0 \%$ & $0 \%$ & $22 \%$ \\
\hline $2000-5000$ & $0 \%$ & $0 \%$ & $0 \%$ & $0 \%$ & $11 \%$ & $0 \%$ & $22 \%$ \\
\hline $5000-20000$ & $0 \%$ & $0 \%$ & $0 \%$ & $0 \%$ & $0 \%$ & $0 \%$ & $0 \%$ \\
\hline $20000-100000$ & $0 \%$ & $0 \%$ & $0 \%$ & $0 \%$ & $0 \%$ & $0 \%$ & $22 \%$ \\
\hline
\end{tabular}

With the help of this it becomes clear that while certain categories account for a minor share of the whole route (Tab. 3), still a significant number of people lose their lives on the road sections here. As an example, the horizontal (e [\%]= 0 -4) sections of small arc radius $(\mathrm{R}[\mathrm{m}]=0-120 \mathrm{~m})$ can be mentioned, which make up $2 \%$ of the route; but $22 \%$ of the number of fatalities occur here.

Besides the fatalities, it is reasonable to investigate the distribution of the total number of injuries. The distribution of all the injuries is still unbalanced, and there are again categories which are overrepresented taking into account the number of records in them. As an example, the horizontal $(\mathrm{e}[\%]=0-4)$ subsections of small arc radius $(\mathrm{R}[\mathrm{m}]=0-120 \mathrm{~m})$ can be mentioned again, which make up $2 \%$ of the route; but $8 \%$ of all the injuries happen here.

\section{Conclusion}

To conclude it can be stated that the evaluation has proven our hypothesis supposing that there is a relationship between the parameters of infrastructure design and transport safety risk. Further statistical analysis is needed to establish the closeness of this relationship and to estimate the functional relationship between the two sets of criterions. These investigations are to be carried out after the extension of the sample, in a further phase of the research.

\section{References}

Baranyai D. (2012) Infrastructure safety survey on the road no. 82. [In Hungarian: A 82-es számú föút közlekedésbiztonsági szempontú felmérése]. Supervised Scientific Essays. Budapest University of Technology and Economics (Supervisor: Tibor Sipos).

Bosurgi G., D'Andrea A., Pellegrino O. (2013) What variables affect to a greater extent the driver's vision while driving? Transport, 28 (4), pp. 331-340.

DOI: $10.3846 / 16484142.2013 .864329$

Dabbour E. (2012) Using logistic regression to identify risk factors causing rollover collisions. International Journal of Traffic and Transport Engineering, 2 (4), pp. 372-379. DOI: $\underline{10.7708 / \text { ijtte.2012.2(4).07 }}$

Holló P., Sipos T., Török Á. (2011) The Hungarian Participation in the EuroRap Program [In Hungarian: Hazai részvétel az EuroRap programban]. Research study, KTI - Institute for Transport Sciences.

Lyche T., Schumacker L. L. (1973) On the convergence of cubic interpolating splines. Spline Functions and Approximation Theory. Birkhauser, pp. 169-189.

Pešić D., Vujanić M., Lipovac K., Antić B. (2013) New method for benchmarking traffic safety level for the territory. Transport, 28 (1), pp. 69-80.

DOI: $\underline{10.3846 / 16484142.2013 .781539}$ 
Podvezko V., Sivilevičius H. (2013) The use of AHP and rank correlation methods for determining the significance of the interaction between the elements of a transport system having a strong influence on traffic safety. Transport, 28 (4), pp. 389-403.

DOI: $10.3846 / 16484142.2013 .866980$

Sipos T., Török Á. (2010) Inspection of the road infrastructure information system [In Hungarian: Forgalmi rend felülviszgálat a megalapozó módszertan szerint]. Research study, KTI - Institute for Transport Sciences.

Török Á. (2013) Simplification of Road Transport Infrastructure Layout for Better Self-Explanation. American Journal of Vehicle Design, 1 (1), pp. 16-20.

DOI: 10.12691/ajvd-1-1-3
Varga J. (1982) Transforming coordinate systems to UNP system [In Hungarian: Átszámitás az Egységes Országos Vetületi rendszer $(E O V)$ és a korábbi vetületi rendszereink között]. Geodézia és Kartográfia. 1982/1. pp. 30-34.

Varga J. (2003) Projecting coordinate systems [In Hungarian: Vetülettan]. Műegyetemi Kiadó, Egyetemi jegyzet 91244.

Wanty D., McLarin M., Davies R., Cenek P. (1995) Application of the Road Geometry Data Aquisition System. 7th World Conference on Transport Research, Sydney, Australia. 